\title{
Preoperative Prognostic Nutritional Index is a Significant Predictor of Survival with Bladder Cancer after Radical Cystectomy: a retrospective study
}

Ding Peng ${ }^{1,2,3,4+}$, Yan-qing Gong ${ }^{1,2,3,4+}$, Han Hao ${ }^{1,2,3,4}$, Zhi-song He $\mathrm{H}^{1,2,3,4}$, Xue-song Li $\mathrm{i}^{1,2,3,4}$, Cui-jian Zhang ${ }^{1,2,3,4^{*}}$ and Li-qun Zhou ${ }^{1,2,3,4^{*}}$

\begin{abstract}
Background: To explore the prognostic significance of preoperative prognostic nutritional index (PNI) in bladder cancer after radical cystectomy and compare the prognostic ability of inflammation-based indices.

Methods: We retrospectively analyzed data for 516 patients with bladder cancer who underwent radical cystectomy in our institution between 2006 to 2012. Clinicopathologic characteristics and inflammation-based indices (PNI, neutrophil/ lymphocyte ratio [NLR], platelet/lymphocyte ratio [PLR], lymphocyte/monocyte ratio [LMR]) were evaluated by pre-treatment measurements. Overall survival (OS) and progression-free survival (PFS) were estimated by the Kaplan-Meier method and compared by log-rank test. Multivariate analysis with a Cox proportional hazards model was used to confirm predictors identified on univariate analysis. The association between clinicopathological characteristics and PNI or NLR was tested.

Results: Among the 516 patients, the median follow-up was 37 months (interquartile range 20 to 56). On multivariate analysis, PNI and NLR independently predicted OS (PNI: hazard ratio $[\mathrm{HR}]=1.668,95 \% \mathrm{Cl}: 1.147-2.425, P=0.007$; NLR: $\mathrm{HR}=1.416,95 \% \mathrm{Cl}: 1.094-2.016, P=0.0149)$ and PFS (PNI: HR $=1.680,95 \% \mathrm{Cl}: 1.092-2.005, P=0.015 ; \mathrm{NLR}: \mathrm{HR}=1.550$, 95\% Cl:1.140-2.388, $P=0.008$ ). Low PNI predicted worse OS for all pathological stages and PFS for T1 and T2 stages. Low PNI was associated with older age (>65 years), muscle-invasive bladder cancer, high American Society of Anesthesiologists grade and anemia.
\end{abstract}

Conclusion: PNI and NLR were independent predictors of OS and PFS for patients with bladder cancer after radical cystectomy and PNI might be a novel reliable biomarker for bladder cancer.

Keywords: Prognostic nutritional index, Bladder cancer, Radical cystectomy, Outcomes

\section{Background}

Radical cystectomy is the standard treatment for localized muscle-invasive bladder cancer (MIBC) and non-muscle invasive bladder cancer (NMIBC) unresponsive to intravesical therapy $[1,2]$. Despite the advances in surgical skills and chemotherapy, the 5-year survival with all bladder cancer is $77.9 \%$ and only $33.0 \%$ and $5.4 \%$ for regional and distant disease [3]. Therefore, prognostic factors for

\footnotetext{
* Correspondence: surgeon_zhang@126.com; zhouliqunmail@sina.com ${ }^{\dagger}$ Equal contributors

${ }^{1}$ Department of Urology, Peking University First Hospital, No. 8, Xishiku Street, Xicheng District, Beijing 100034, China

Full list of author information is available at the end of the article
}

bladder cancer are needed for treatment decision making and postoperative monitoring.

Several preoperative hematological parameters have been reported as prognostic biomarkers for bladder cancer. Prognostic indicators suggested have been based on albumin and C-reactive protein levels and platelet and blood count, such as neutrophil/lymphocyte ratio [NLR], platelet/lymphocyte ratio (PLR) and lymphocyte/monocyte ratio (LMR) [4-8]. In addition, prognostic nutritional index (PNI), which combines nutrition and inflammation status, has been found to predict outcomes in various cancers [9-14]. However, no study has evaluated the prognostic value of PNI in bladder cancer. 
This study aimed to explore the prognostic significance of preoperative PNI in bladder cancer patients after radical cystectomy and compare the prognostic ability of inflammation-based indices.

\section{Methods}

We retrospectively reviewed the medical data for 571 consecutive bladder cancer patients who underwent radical cystectomy between 2006 and 2012 in Peking University First Hospital. We excluded 55 patients with non-bladder cancer, were lost to follow-up or had a history of disease that could affect blood cell lines. Therefore, we analyzed data for 516 patients. Clinicopathological data including gender, age, smoking status, history of Diabetes Mellitus, hypertension, heart and cerebrovascular disease, histology type, operation style (open or laparoscopic), American Society of Anesthesiologists (ASA) grade, postoperative complications (including prolonged ileus, fever, wound infection, wound dehiscence, gastrointestinal bleeding, cardiac arrhythmia, myocardial infarction, urinary leakage, pneumonia and death), pathological lymph-node status, pathological $\mathrm{T}$ stage and differential grade were obtained from the medical database. Histological subtype was diagnosed by at least 2 experienced pathologists on the basis of the 1973 WHO criteria, and TNM staging was assessed by the American Joint Committee on Cancer cancer staging system (7th edition, 2010). Hematological factors including preoperative hemoglobin and albumin levels and complete blood counts were collected within 3 days before surgery. This study was approved by the Institutional Review Board of Peking University First Hospital.

\section{Statistical analysis}

The endpoint of the study was overall survival (OS), calculated from the day of surgery to the time of all-caused death, and progression-free survival (PFS), as the period from the date of surgery to the time of disease recurrence, metastasis or death. All continuous data are shown as median (interquartile range [IQR]). PNI was calculated as albumin level $(\mathrm{g} / \mathrm{L})+5 \times$ lymphocyte count $\left(10^{9} / \mathrm{L}\right)$, PLR as platelet/lymphocyte ratio, NLR as neutrophil/lymphocyte count, and LMR as lymphocyte/ monocyte count. Receiver operating characteristic (ROC) curve analysis was used to compare the prognostic ability of each indicator for each OS and PFS event according to the area under the ROC curve (AUC) and to determine the best cutoff points. For each prognostic factor, patients were divided into 2 groups according to cutoffs. The Kaplan-Meier survival method were used to draw OS and PFS curves. Univariate analysis involved the log-rank test. Factors significant on univariate analysis were included in Cox proportional-hazards multivariate models, estimating hazard ratios (HRs) and 95\% CIs. The association of clinicopathological characteristics
Table 1 Baseline clinicopathological characteristics of patients with bladder cancer

\begin{tabular}{|c|c|}
\hline Characteristics & Total $n=516$ \\
\hline Age, years, median (IQR) & $66(35-91)$ \\
\hline Female sex, $\mathrm{n}(\%)$ & $80(15.5 \%)$ \\
\hline \multicolumn{2}{|l|}{ Histology type, n (\%) } \\
\hline UC & $488(94.6 \%)$ \\
\hline NUC & $28(5.4 \%)$ \\
\hline \multicolumn{2}{|l|}{ Pathological grade, n (\%) } \\
\hline 2 & $131(25.4 \%)$ \\
\hline 3 & $385(74.6 \%)$ \\
\hline Smoking history & $161(31.2 \%)$ \\
\hline Diabetes Mellitus & $56(10.9 \%)$ \\
\hline Hypertension & $149(28.9 \%)$ \\
\hline Heart disease & $55(10.7 \%)$ \\
\hline Cerebrovascular disease & 17 (3.3\%) \\
\hline \multicolumn{2}{|l|}{ pT stage, n (\%) } \\
\hline 1 & $162(31.4 \%)$ \\
\hline 2 & $161(31.2 \%)$ \\
\hline 3 & 105 (20.3\%) \\
\hline 4 & $88(17.1 \%)$ \\
\hline \multicolumn{2}{|l|}{ pN status, n (\%) } \\
\hline negative & $81(15.7 \%)$ \\
\hline positive & 435 (84.3\%) \\
\hline \multicolumn{2}{|l|}{ ASA grade, $n(\%)$} \\
\hline $1 \& 2$ & $436(84.5 \%)$ \\
\hline $3 \& 4$ & $80(15.5 \%)$ \\
\hline \multicolumn{2}{|l|}{ Surgery style } \\
\hline open & 409 (79.3\%) \\
\hline laparoscopic & 107 (20.7\%) \\
\hline \multicolumn{2}{|l|}{ Postoperative complications } \\
\hline present & $73(8.3 \%)$ \\
\hline absent & 443 (91.7\%) \\
\hline \multicolumn{2}{|l|}{ Anemia } \\
\hline present & $144(27.9 \%)$ \\
\hline absent & 372 (72.1\%) \\
\hline \multicolumn{2}{|l|}{ Hypoalbuminemia } \\
\hline present & $74(14.3 \%)$ \\
\hline absent & $442(85.7 \%)$ \\
\hline NLR, median (IQR) & $2.34(1.74-3.49)$ \\
\hline PLR, median (IQR) & $133.8(98.22-180.22)$ \\
\hline LMR, median (IQR) & $4.37(3.30-5.72)$ \\
\hline PNI, median (IQR) & $47.8(44.66-51.58)$ \\
\hline
\end{tabular}

UC urothelial carcinoma, NUC non-urothelial carcinoma, ASA American Society of Anesthesiologists, PNI prognostic nutritional index, NLR neutrophillymphocyte ratio, $P L R$ platelet-lymphocyte ratio, $L M R$ lymphocyte-monocyte ratio, $I Q R$, interquartile range 
and PNI or NLR was tested by Mann-Whitney U-test. Statistical significance was considered with two-sided $p<0.05$. All statistical analyses involved use of SPSS v21.0 (IBM Inc. Chicago, IL, USA).

\section{Results}

A total of 516 patients (median age 66 years, IQR 5773; 80 females [15.5\%]) were included in this study. The median follow-up was 37 months (IQR 20-56). At the end of follow-up, 164 (31.8\%) patients had died from any cause and 188 (36.4\%) showed disease progression. The clinicopathological characteristics of all patients are shown in Table 1. The tumor stage of all patients was T1 for 162 (31.4\%), T2 for 161 (31.2\%), T3 for 105 (20.3\%), and T4 for 88 (17.1\%). The 3- and 5-year OS was $75.3 \%$ and $69 \%$ and PFS was $63.7 \%$ and $59.7 \%$. Median NLR was 2.34 (IQR 1.74-3.49), PLR: 133.8 (98.22180.22), LMR: 4.37 (3.30-5.72), PNI: 47.8 (44.66-51.58).

The AUC value was greater for PNI than the other 3 factors for estimating OS and PFS (Fig. 1). We determined the cutoff values for the 4 factors for OS and PFS by calculating the maximum Youden index (OS: PNI-46.025, NLR-2.303, PLR-136.125, LMR-4.099; PFS: PNI-47.20, NLR-2.288, PLR-135.247, LMR-4.099). Then patients were divided into low- and high-risk groups according to the ratios.

On univariate analysis, significant indicators for both OS and PFS were older age ( $>65$ years), high tumor grade, pT2 or greater, positive lymph node status, history of heart and cerebrovascular disease, high ASA grade, hypoalbuminemia, anemia, postoperative complications and the 4 indicators (PNI, PLR, NLR, LMR) (Table 2). As compared with high PNI, low PNI was associated with worse OS and PFS (Fig. 2).

Thus, these variables were included in a Cox proportional-hazards model. Independent risk factors for OS were older age ( $>65$ years; $\mathrm{HR}=1.615,95 \%$ CI:1.116-2.337, $P=0.011)$, pT2 or greater $(\mathrm{HR}=2.796$, 95\% CI:1.700-4.598, $P<0.001$ ), positive lymph node status $(\mathrm{HR}=1.682,95 \% \mathrm{CI}: 1.141-2.480, P=0.009)$, high ASA grade $(\mathrm{HR}=1.641,95 \% \mathrm{CI}: 1.113-2.418, P=0.012)$, postoperative complications $(\mathrm{HR}=1.607,95 \% \mathrm{CI}$ : 1.076-2.400, $P=0.020)$,low PNI (HR $=1.668,95 \% \mathrm{CI}$ : $1.147-2.425, P=0.007)$ and high NLR (HR $=1.416,95 \%$ CI:1.094-2.016, $P=0.0149)$. For PFS, independent risk factors were pT2 or greater (HR $=2.560,95 \%$ CI:1.677$3.906, P<0.001)$, positive lymph node status $(\mathrm{HR}=1.871$, 95\% CI:1.306-2.680, $P=0.001)$, high ASA grade $(\mathrm{HR}=1.561,95 \%$ CI:1.086-2.243, $P=0.016)$, low PNI $(\mathrm{HR}=1.680,95 \% \mathrm{CI}: 1.092-2.005, P=0.015)$ and high NLR (HR $=1.550,95 \%$ CI:1.140-2.388, $P=0.008)$.

Inflammatory status may be affected by disease stage. Therefore, we classified patients into 3 groups by pathological stage (Fig. 3). OS was shorter for patients with low than high PNI with all stages (stage 1: $P=0.042$, stage 2: $P=0.002$, stages 3 and $4: P=0.012$ ). However, PFS was shorter for patients with low PNI only with stage 1 or 2 disease (stage $1: P=0.014$, stage 2 : $P=0.001$, stages 3 and 4: $P=0.141$ ).

We then assessed PNI and NLR for patients with different clinicopathological characteristics. Low PNI was
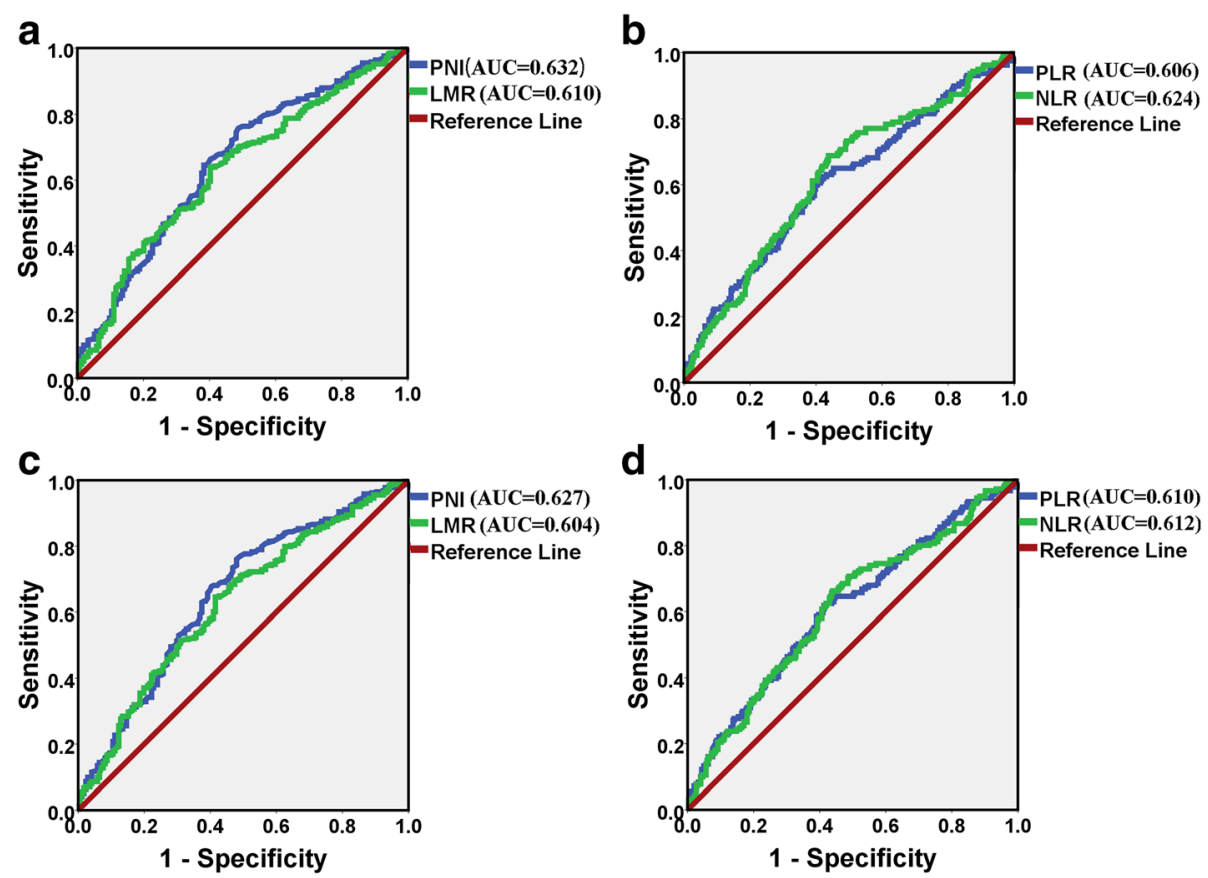

Fig. 1 Receiver operating characteristic (ROC) curves for overall survival $\mathbf{a}, \mathbf{b}$ and progression-free survival $\mathbf{c}, \mathbf{d}$ for PNI,LMR,PLR and NLR 
Table 2 Univariate and multivariate analyses of prognostic factors for overall survival and progression-free survival

\begin{tabular}{|c|c|c|c|}
\hline \multirow[t]{2}{*}{ Variable } & \multirow{2}{*}{$\begin{array}{l}\text { Univariate } \\
P \text { value }\end{array}$} & \multicolumn{2}{|l|}{ Multivariate } \\
\hline & & HR $(95 \% \mathrm{Cl})$ & $P$ Value \\
\hline \multicolumn{4}{|l|}{ Overall survival } \\
\hline Age (>65 vs. $\leq 65)$ & $<0.001$ & $1.615(1.116-2.337)$ & 0.011 \\
\hline Gender (male vs. female) & 0.264 & & \\
\hline Histology type (NUC vs. UC) & 0.363 & & \\
\hline Pathological grade (3 vs. 2) & $<0.001$ & & \\
\hline pT (pT2 or greater vs. pT1) & $<0.001$ & $2.796(1.700-4.598)$ & $<0.001$ \\
\hline pN status (positive vs. negative) & $<0.001$ & $1.682(1.141-2.480)$ & 0.009 \\
\hline Smoking history & 0.937 & & \\
\hline Hypertension & 0.480 & & \\
\hline Diabetes Mellitus & 0.534 & & \\
\hline Heart disease & 0.018 & & \\
\hline Cerebrovascular disease & 0.032 & & \\
\hline ASA grade ( $3 \& 4$ vs. $1 \& 2)$ & $<0.001$ & $1.641(1.113-2.418)$ & 0.012 \\
\hline Hypoalbuminemia & $<0.001$ & & \\
\hline Anemia & $<0.001$ & & \\
\hline Postoperative complications & 0.003 & $1.607(1.076-2.400)$ & 0.020 \\
\hline PNI (low vs. high) & $<0.001$ & $1.668(1.147-2.425)$ & 0.007 \\
\hline PLR (high vs. low) & $<0.001$ & & \\
\hline NLR (high vs. low) & $<0.001$ & $1.416(1.094-2.016)$ & 0.014 \\
\hline LMR (low vs. high) & $<0.001$ & & \\
\hline \multicolumn{4}{|l|}{ Progression-free survival } \\
\hline Age (>65 vs. $\leq 65)$ & $<0.001$ & & \\
\hline Gender (male vs. female) & 0.304 & & \\
\hline Histology type (NUC vs. UC) & 0.683 & & \\
\hline Pathological grade (3 vs. 2) & $<0.001$ & & \\
\hline pT (pT2 or greater vs. pT1) & $<0.001$ & $2.560(1.677-3.906)$ & $<0.001$ \\
\hline pN status (positive vs. negative) & $<0.001$ & $1.871(1.306-2.680)$ & 0.001 \\
\hline Smoking history & 0.952 & & \\
\hline Hypertension & 0.604 & & \\
\hline Diabetes Mellitus & 0.681 & & \\
\hline Heart disease & 0.012 & & \\
\hline Cerebrovascular disease & 0.033 & & \\
\hline ASA grade (3\&4 vs. 1\&2) & $<0.001$ & $1.561(1.086-2.243)$ & 0.016 \\
\hline Hypoalbuminemia & $<0.001$ & & \\
\hline Anemia & $<0.001$ & & \\
\hline Postoperative complications & 0.004 & & \\
\hline PNI (low vs. high) & $<0.001$ & $1.680(1.092-2.005)$ & 0.011 \\
\hline PLR (high vs. low) & $<0.001$ & & \\
\hline NLR (high vs. low) & $<0.001$ & $1.550(1.140-2.388)$ & 0.008 \\
\hline LMR (low vs. high) & $<0.001$ & & \\
\hline
\end{tabular}

UC urothelial carcinoma, NUC non-urothelial carcinoma, ASA American Society of Anesthesiologists, PNI prognostic nutritional index, NLR neutrophil-lymphocyte ratio, PLR platelet-lymphocyte ratio, LMR lymphocyte-monocyte ratio

Significant values are in bold 

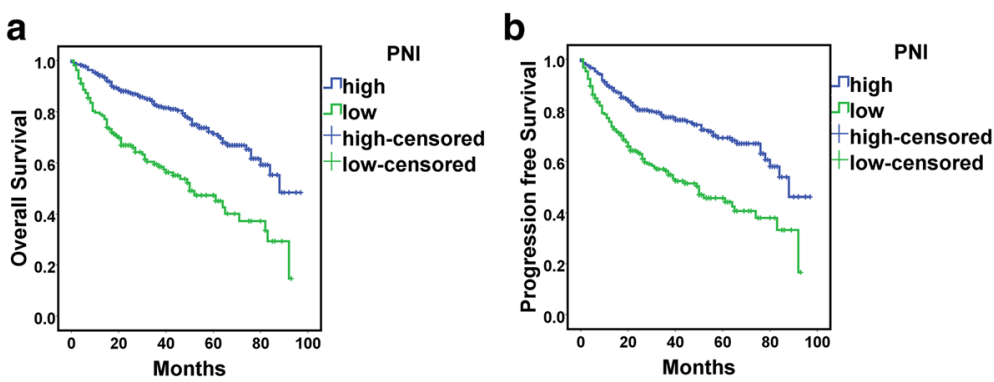

Fig. 2 Kaplan-Meier survival curves for overall survival a and progression-free survival b for PNI

associated with older age ( $>65$ years), pT2 or greater, high ASA grade and anemia (Table 3). Meanwhile, elevated NLR level was associated with older age ( $>65$ years), high grade and ASA grade, pT2 or greater, positive lymph node status, cerebrovascular disease and anemia.

\section{Discussion}

Inflammation-based ratios are representative biomarkers of host inflammation response that predict the prognosis of cancer. In this study, we assessed the prognostic value of PNI and compared the prognostic ability of inflammationbased indices in bladder cancer patients who underwent radical cystectomy. By univariate and multivariate analyses, we found that PNI and NLR as prognostic and independent risk factors for both OS and PFS.

Immune cells play an important role in tumorigenesis, development and metastasis. Neutrophils can interact with tumor cells and secrete cytokines and chemokines which could promote tumor proliferation, angiogenesis and metastasis [15]. For example, neutrophils could secrete vascular endothelial growth factor (VEGF) into the circulation and VEGF is essential for tumor angiogenesis, metastasis and drug resistance. On the other hand, the role of lymphocytes is mainly through the tumor immune surveillance and tumor cell clearance to inhibit the tumorigenesis and development. In addition, neutrophils in the tumor microenvironment could also interact with lymphocytes and reduce the antitumor effects of activated $\mathrm{T}$ cells and natural killer (NK) cells $[16,17]$. Therefore, an elevated NLR represent a neutrophilia and lymphocytopenia, which reflected the imbalance in the immune response. As a simple systemic inflammation response marker, NLR has been recommended associated with worse recurrence-free, disease-specific, and overall survival in patients with bladder cancer [18]. In the present study, NLR was independent risk factor for OS and PFS for bladder cancer patients and this is consistent with previous studies.

In addition to inflammation response, nutrition status is another important prognostic impact for cancer patients. Hypoalbuminemia has been demonstrated associated with cancer recurrence and decreased OS in bladder cancer patients after RC $[19,20]$. Moreover, increasing evidence indicated that hypoalbuminemia in cancer patients is related with inflammatory imbalance as well as cancer cachexia. Lambert et al. [19] evaluated 187 bladder cancer patients and found $31(16.5 \%)$ patients were in the low-albumin cohort(albumin $<3.5 \mathrm{~g} / \mathrm{dL}$ ). The OS was lower in low-

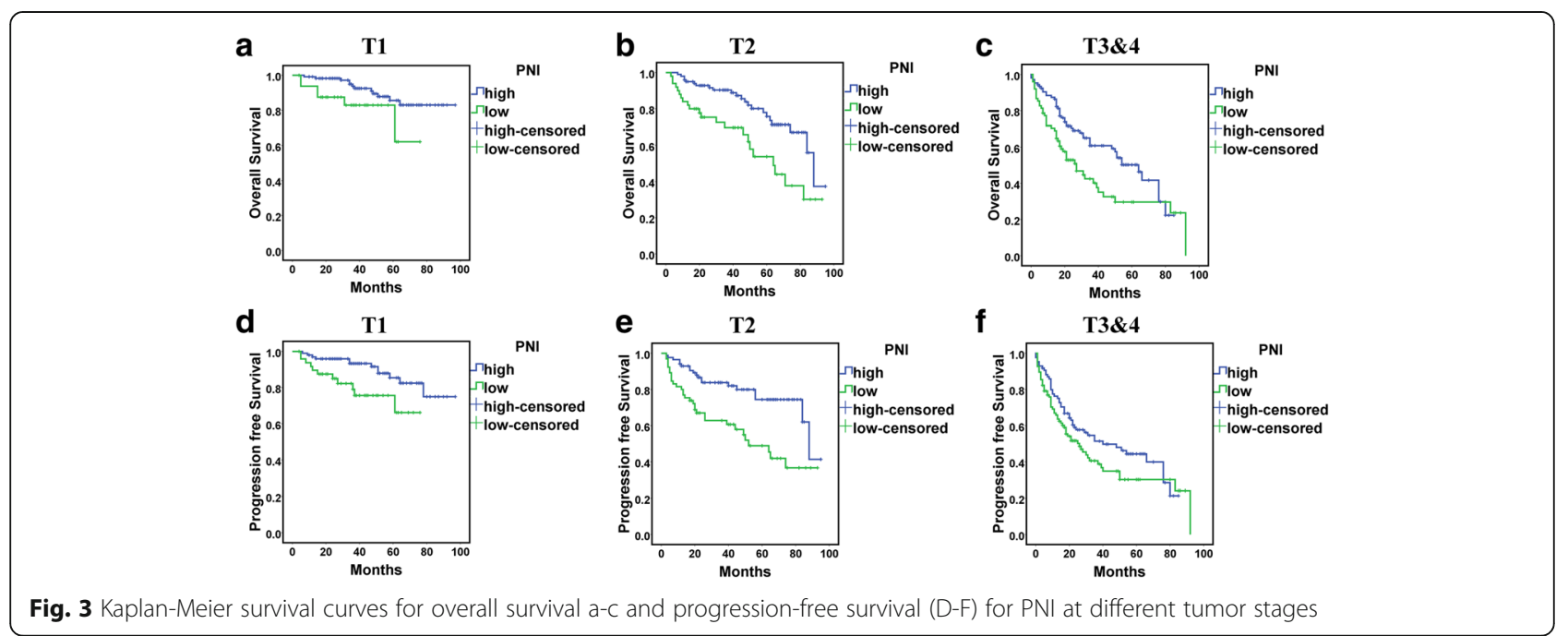


Table 3 Relationship between clinicopathological characteristics and PNI or NLR

\begin{tabular}{|c|c|c|c|c|c|}
\hline Variable & $\mathrm{N}$ & $\mathrm{PNI}$ & $P$ value & NLR & $P$ value \\
\hline Gender & & & 0.068 & & 0.406 \\
\hline male & 436 & $48.05(44.95-51.75)$ & & $2.39(1.77-3.47)$ & \\
\hline female & 80 & $46.90(43.87-50.05)$ & & $2.21(1.59-3.97)$ & \\
\hline Age, years & & & $<0.001$ & & $<0.001$ \\
\hline$>65$ & 278 & $46.92(43.33-49.68)$ & & $2.61(1.95-3.91)$ & \\
\hline$\leq 65$ & 238 & $49.62(46.25-53.22)$ & & $2.15(1.68-2.92)$ & \\
\hline Histology type & & & 0.396 & & 0.667 \\
\hline$U C$ & 488 & $47.80(44.65-51.55)$ & & $2.33(1.76-3.49)$ & \\
\hline NUC & 28 & $48.95(46.15-53.05)$ & & $2.67(1.66-3.54)$ & \\
\hline Pathological grade & & & 0.086 & & 0.048 \\
\hline 2 & 131 & $48.65(45.25-52)$ & & $2.24(1.70-2.90)$ & \\
\hline 3 & 385 & $47.65(44.52-51.15)$ & & $2.43(1.76-3.73)$ & \\
\hline T stage & & & $<0.001$ & & $<0.001$ \\
\hline pT2 or greater & 354 & $47.35(44.05-50.65)$ & & $2.52(1.90-3.93)$ & \\
\hline pT1 & 162 & $49.00(46.20-52.97)$ & & $2.06(1.63-2.68)$ & \\
\hline N status & & & 0.250 & & 0.041 \\
\hline negative & 435 & $48.00(44.90-51.65)$ & & $2.29(1.71-3.42)$ & \\
\hline positive & 81 & $47.10(43.87-51.02)$ & & $2.50(1.99-3.96)$ & \\
\hline Smoking & & & 0.109 & & 0.524 \\
\hline no & 355 & $47.55(44.40-51.57)$ & & $2.39(1.72-3.64)$ & \\
\hline yes & 161 & $48.70(45.42-51.60)$ & & $2.33(1.81-3.17)$ & \\
\hline Diabetes Mellitus & & & 0.948 & & 0.179 \\
\hline no & 460 & $47.8(44.75-51.60)$ & & $2.32(1.73-3.44)$ & \\
\hline yes & 56 & $48(44.50-51.28)$ & & $2.72(1.81-3.99)$ & \\
\hline Hypertension & & & 0.862 & & 0.067 \\
\hline no & 367 & $47.80(44.75-51.65)$ & & $2.27(1.71-3.19)$ & \\
\hline yes & 149 & $48.02(44.57-51.15)$ & & $2.50(1.82-3.75)$ & \\
\hline Heart disease & & & 0.177 & & 0.516 \\
\hline no & 461 & $47.97(44.90-51.65)$ & & $2.31(1.73-3.53)$ & \\
\hline yes & 55 & $47.22(43.70-50.56)$ & & $2.48(1.78-3.09)$ & \\
\hline Cerebrovascular disease & & & 0.277 & & 0.045 \\
\hline no & 499 & $47.95(44.71-51.6)$ & & $2.32(1.72-3.44)$ & \\
\hline yes & 17 & $47.10(42.77-49.10)$ & & $2.69(2.22-4.04)$ & \\
\hline Surgery style & & & 0.278 & & 0.806 \\
\hline open & 409 & $47.95(44.9051 .75)$ & & $2.37(1.73-3.65)$ & \\
\hline laparoscopic & 107 & $47.60(44.2051 .25)$ & & $2.28(1.80-3.20)$ & \\
\hline Postoperative complications & & & 0.129 & & 0.730 \\
\hline no & 443 & $48.00(45.05-51.55)$ & & $2.33(1.76-3.47)$ & \\
\hline yes & 73 & 46.35 (43.75-51.78) & & $2.37(1.59-3.61)$ & \\
\hline ASA grade & & & $<0.001$ & & 0.031 \\
\hline $1 \& 2$ & 436 & $48.05(45.25-51.90)$ & & $2.30(1.725-3.21)$ & \\
\hline $3 \& 4$ & 80 & $46.00(42.50-49.37)$ & & $2.53(2.05-3.99)$ & \\
\hline
\end{tabular}


Table 3 Relationship between clinicopathological characteristics and PNI or NLR (Continued)

\begin{tabular}{llll}
\hline Anemia & & $<0.001$ & $<0.001$ \\
no & 372 & $49.07(46.502 .93)$ & $2.23(1.69-2.96)$ \\
yes & 144 & $44.55(40.90-47.38)$ & $3.01(2.00-4.42)$ \\
\hline
\end{tabular}

UC urothelial carcinoma, NUC non-urothelial carcinoma, ASA American Society of Anesthesiologists, PNI prognostic nutritional index, NLR neutrophil-lymphocyte ratio, PLR platelet-lymphocyte ratio, LMR lymphocyte-monocyte ratio

Significant values are in bold

albumin group than those with normal albumin and the complication rates were also higher in the group with low albumin. Djaladat et al. [20] reported 197 patients (13.4\%) from a 1964 bladder cancer patients cohort had a low albumin level $(<3.5 \mathrm{~g} / \mathrm{dL})$. In multivariable analysis for OS and RFS, low albumin remained independently associated with decreased OS and RFS. In our study, we observed 74 (13.66\%) patients with albumin $<3.5 \mathrm{~g} / \mathrm{dL}$ and hypoalbuminemia was predictor for OS and PFS in univariate analysis. Those findings support the importance of albumin level in prognosis for bladder cancer.

PNI was first created by Onodera et al. to evaluate the inflammation and nutrition status of patients after gastrointestinal surgery [21]. Because PNI is calculated by serum albumin and lymphocyte count, decreased PNI represents hypoalbuminemia and decreased lymphocyte count, both responsible for worse outcomes in cancer patients. Since then, it has been a predictor of survival in several solid tumors including colorectal, breast, oesophageal, hepatocellular, renal and lung cancer [9-11, 13]. Ryuma Tokunaga et al. [22] compared the systemic inflmmatory and nutritional scores for colorectal cancer patients after curative resection and found PNI was a better predictive score than NLR, PLR and CRP.

Several studies also have compared inflammation-based ratios to find a good marker for bladder cancer and NLR or LMR was reported as the best [7,23, 24]. These results differing from ours may be due to differences in patient characteristics and populations. In our study, NLR but not LMR remained an independent factor of survival on multivariate analysis, which may support the significance of NLR. In addition, these studies did not include PNI, a comprehensive and easily measured indicator. Therefore, we investigated PNI in the prognosis of bladder cancer and found it as a predictor of OS and PFS.

Our study has some limitations. First, this was a retrospective observational study and the inherent retrospective and nonrandomized nature may have led to selection bias. Second, we did not measure blood cell counts at regular intervals after radical cystectomy and could not explore the predictive value of the change in inflammation-based biomarkers pre- and post-radical cystectomy. Finally, this study was a single, tertiary-care institution study and our findings require well-controlled and multiple-institution studies for external validation.

\section{Conclusion}

Both PNI and NLR are independent risk factors for OS and PFS. PNI may be an additional easily measured biomarker for stratifying risk preoperatively for bladder cancer patients who undergo radical cystectomy.

\section{Abbreviations}

PNI: Prognostic nutritional index; OS: Overall survival; PFS: Progression free survival; MIBC: Muscle-invasive bladder cancer; NMIBC: Non-muscle invasive bladder cancer; IQR: Interquartile range; ASA: American Society of Anesthesiologists; ROC: Receiver operating characteristic; AUC: Area under the receiver operating characteristic curve

\section{Acknowledgements}

Not applicable.

\section{Authors' contribution}

$L Z, C Z$, DP, and $Y G$ conceived and designed project. $H H, X L, Z H, D P$ and $Y G$ collected data. DP and YG analyzed the data. DP, CZ, YG and LZ wrote the manuscript. All authors read and approved the final manuscript.

\section{Funding}

This work was supported by the National Natural Science Foundation of China (Grant Number: 81372746 and 81672546).

\section{Availability of data and materials}

The data and charts involved in this article are available from the corresponding author if there are reasonable reasons.

Competing interests

All authors in this article declare that they have no competing interests.

\section{Consent for publication}

Not applicable.

\section{Ethics approval and consent to participate}

Written informed consents for their information to be stored and used in the hospital database were obtained prior to data collection and the study was approved by the ethics committee of Peking University First Hospital. The study was conducted in accordance with the Declaration of Helsinki to protect the personal data.

\section{Publisher's Note}

Springer Nature remains neutral with regard to jurisdictional claims in published maps and institutional affiliations.

\section{Author details}

'Department of Urology, Peking University First Hospital, No. 8, Xishiku Street, Xicheng District, Beijing 100034, China. ${ }^{2}$ Institute of Urology, Peking University, Beijing 100034, China. ${ }^{3}$ National Urological Cancer Center, Beijing 100034, China. ${ }^{4}$ Urogenital Diseases (male) Molecular Diagnosis and Treatment Center, Peking University, Beijing 100034, China. 
Received: 20 December 2016 Accepted: 17 May 2017

Published online: 02 June 2017

\section{References}

1. Babjuk M, Böhle A, Burger M, Capoun O, Cohen D, Compérat EM, et al. EAU Guidelines on Non-Muscle-invasive Urothelial Carcinoma of the Bladder: Update 2016. Eur Urol. 2017;71(3):447-61.

2. Alfred Witjes J, Lebret T, Compérat EM, Cowan NC, De Santis M, Bruins HM, et al. Updated 2016 EAU Guidelines on Muscle-invasive and Metastatic Bladder Cancer. Eur Urol. 2017;71(3):462-75.

3. DeSantis $C E$, Lin CC, Mariotto AB, Siegel RL, Stein KD, Kramer JL, et al. Cancer treatment and survivorship statistics, 2014. CA Cancer J Clin. 2014; 64(4):252-71.

4. Moschini M, Suardi N, Pellucchi F, Rocchini L, La Croce G, Capitanio U, et al. Impact of preoperative thrombocytosis on pathological outcomes and survival in patients treated with radical cystectomy for bladder carcinoma. Anticancer Res. 2014;34(6):3225-30.

5. Eggers H, Seidel C, Schrader AJ, Lehmann R, Wegener G, Kuczyk MA, et al. Serum C-reactive protein: a prognostic factor in metastatic urothelial cancer of the bladder. Med Oncol. 2013;30(4):705.

6. Temraz S, Mukherji D, Farhat ZA, Nasr R, Charafeddine M, Shahait M, et al. Preoperative lymphocyte-to-monocyte ratio predicts clinical outcome in patients undergoing radical cystectomy for transitional cell carcinoma of the bladder: a retrospective analysis. BMC Urol. 2014:14:76.

7. Zhang GM, Zhu Y, Luo L, Wan FN, Zhu YP, Sun LJ, et al. Preoperative lymphocyte-monocyte and platelet-lymphocyte ratios as predictors of overall survival in patients with bladder cancer undergoing radical cystectomy. Tumour Biol. 2015;36(11):8537-43.

8. Kawahara T, Furuya K, Nakamura M, Sakamaki K, Osaka K, Ito H, et al. Neutrophil-to-lymphocyte ratio is a prognostic marker in bladder cancer patients after radical cystectomy. BMC Cancer. 2016;16:185.

9. Jeon HG, Choi DK, Sung HH, Jeong BC, Seo SI, Jeon SS, et al. Preoperative Prognostic Nutritional Index is a Significant Predictor of Survival in Renal Cell Carcinoma Patients Undergoing Nephrectomy. Ann Surg Oncol. 2016; 23(1):321-7.

10. Mohri T, Mohri Y, Shigemori T, Takeuchi K, Itoh Y, Kato T. Impact of prognostic nutritional index on long-term outcomes in patients with breast cancer. World J Surg Oncol. 2016;14(1):170.

11. Hong S, Zhou T, Fang W, Xue C, Hu Z, Qin T, et al. The prognostic nutritional index (PNI) predicts overall survival of small-cell lung cancer patients. Tumour Biol. 2015;36(5):3389-97.

12. Pinato DJ, North BV, Sharma R. A novel, externally validated inflammationbased prognostic algorithm in hepatocellular carcinoma: the prognostic nutritional index (PNI). Brit J Cancer. 2012;106(8):1439-45.

13. Hofbauer SL, Pantuck AJ, de Martino M, Lucca I, Haitel A, Shariat SF, et al. The preoperative prognostic nutritional index is an independent predictor of survival in patients with renal cell carcinoma. Urol Oncol. 2015;33(2):68.e61-7.

14. Nozoe T, Kimura Y, Ishida M, Saeki H, Korenaga D, Sugimachi K. Correlation of pre-operative nutritional condition with post-operative complications in surgical treatment for oesophageal carcinoma. Eur J Surg Oncol. 2002;28(4): 396-400.

15. Bindea G, Mlecnik B, Fridman WH, Pages F, Galon J. Natural immunity to cancer in humans. Curr Opin Immunol. 2010;22(2):215-22.

16. Hanahan D, Weinberg RA. Hallmarks of cancer: the next generation. Cell. 2011:144(5):646-74.

17. Mantovani A, Allavena P, Sica A, Balkwill F. Cancer-related inflammation. Nature. 2008:454(7203):436-44

18. Mano R, Baniel J, Shoshany O, Margel D, Bar-On T, Nativ O, et al. Neutrophilto-lymphocyte ratio predicts progression and recurrence of non-muscleinvasive bladder cancer. Urol Oncol. 2015;33(2):67.e61-7.

19. Lambert JW, Ingham M, Gibbs BB, Given RW, Lance RS, Riggs SB. Using preoperative albumin levels as a surrogate marker for outcomes after radical cystectomy for bladder cancer. Urology. 2013;81(3):587-92.

20. Djaladat H, Bruins HM, Miranda G, Cai J, Skinner EC, Daneshmand S. The association of preoperative serum albumin level and American Society of Anesthesiologists (ASA) score on early complications and survival of patients undergoing radical cystectomy for urothelial bladder cancer. BJU Int. 2014;113(6):887-93.

21. Onodera T, Goseki N, Kosaki G. Prognostic nutritional index in gastrointestinal surgery of malnourished cancer patients. Nihon Geka Gakkai Zasshi. 1984;85(9):1001-5.
22. Tokunaga R, Sakamoto Y, Nakagawa S, Izumi D, Kosumi K, Taki K, et al. Comparison of systemic inflammatory and nutritional scores in colorectal cancer patients who underwent potentially curative resection. Int J Clin Oncol. 2017;

23. Bhindi B, Hermanns T, Wei Y, Yu J, Richard PO, Wettstein MS, et al. Identification of the best complete blood count-based predictors for bladder cancer outcomes in patients undergoing radical cystectomy. $\mathrm{Br} \mathrm{J}$ Cancer. 2016;114(2):207-12

24. Lee SM, Russell A, Hellawell G. Predictive value of pretreatment inflammation-based prognostic scores (neutrophil-to-lymphocyte ratio, platelet-to-lymphocyte ratio, and lymphocyte-to-monocyte ratio) for invasive bladder carcinoma. Kor J Urol. 2015;56(11):749-55.

\section{Submit your next manuscript to BioMed Central and we will help you at every step:}

- We accept pre-submission inquiries

- Our selector tool helps you to find the most relevant journal

- We provide round the clock customer support

- Convenient online submission

- Thorough peer review

- Inclusion in PubMed and all major indexing services

- Maximum visibility for your research

Submit your manuscript at www.biomedcentral.com/submit 